\title{
O AMBIENTE SOCIOMORAL: IMPLICAÇÕES DAS CONCEPÇÕES TRADICIONAL E CONSTRUTIVISTA
}

${ }^{1}$ Stephanie Lee Basile Barboza Caseiro, ${ }^{1}$ Felipe Pacca, Julia Neves Ferreira, ${ }^{2}$ Camila Pavanelli, ${ }^{2}$ leda Alves Lulio, ${ }^{2}$ Luciana Ap. Nogueira, ${ }^{1}$ Raul Aragão Martins.

Universidade Estadual Paulista - UNESP, Pós-graduação em Educação, Marília, SP. E-mail: stephanielee 1@hotmail.com.

\section{RESUMO}

Os anos iniciais do Ensino Fundamental possuem um papel importante no desenvolvimento moral, visto que é a partir desta fase que os indivíduos começam a desenvolver noções mais elaboradas de regras, justiça e resolução de conflitos. É essencial que as escolas contribuam com a formação moral de seus alunos. Tendo como base a teoria da moralidade de Jean Piaget, este estudo descreve o ambiente de duas instituições de ensino particulares e as estratégias utilizadas pelos educadores na mediação dos conflitos interpessoais de seus alunos. A metodologia utilizada foi observação das relações de convívio, entre turmas dos anos iniciais do Ensino Fundamental. Os resultados indicam diferença no ambiente de ambas as escolas e também nas atitudes dos educadores mediante a resolução dos conflitos e pequenas desavenças. Concluímos que as relações interpessoais estabelecidas na escola, proporcionadas pelos educadores, influenciam na formação do ambiente sociomoral e no desenvolvimento da moral do aluno.

Palavras-chave: Resolução de conflitos; Desenvolvimento moral; Ano Inicial do ensino fundamental; Construtivismo.

\section{SOCIOMORAL ENVIRONMENT: IMPLICATIONS OF TRADITIONAL AND CONSTRUCTIVIST CONCEPTS}

\begin{abstract}
The first years of elementary school play an important role on children moral development, considering that people start to develop more elaborated awareness of rules, justice and conflict solutions at this point of life. Bearing this in mind, it is essential that schools contribute to their students' moral formation, making them into independent and critical citizens. Taking Jean Piaget's morality theory into consideration, this study describes the environment of two private schools and the strategies used by educators to mediate interpersonal conflicts among their students. The methodology includes observations of interaction relations among groups belonging to the first years of elementary school. The results indicate a noticeable difference in the environment of both schools, as well as in the educators' behavior towards conflict solutions and disagreements. Thus, we can conclude that the interpersonal relations established at school, provided by the educators, influence on the formation of sociomoral environment and, as a consequence, on the student's moral development.
\end{abstract}

Keywords: Conflict solutions; moral development; first years of elementary school; Constructivism. 


\section{INTRODUÇÃO}

Constantemente percebermos que as relações humanas são rodeadas por conflitos, visto que, a diversidade e divergências de crenças e opiniões geram discordâncias e atritos entre os indivíduos. Entretanto, é por meio de tais situações que os envolvidos têm a oportunidade de lidar com o que é diferente deles. Tratando-se especificamente do ambiente escolar, local onde normalmente se empreendem esforços para obter a ordem e a disciplina, quando se pensa em conflitos interpessoais, logo são associados a algo ruim que deve ser evitado, vistos como prejudiciais ao desenvolvimento do aluno e ao bom andamento das aulas. Dessa forma, a ideia de ambiente sociomoral da maioria das escolas requer que os alunos sejam passivos e obedientes.

Piaget (1975/1985, apud DE VRIES; ZAN, 1998) considera o conflito como o fator mais influente na aquisição de novas estruturas de conhecimento. Sendo assim, quando ocorre um conflito, o sujeito pode ser motivado, pelo desequilíbrio causado, a refletir sobre maneiras distintas de restabelecer a reciprocidade, ou seja, a pensar na perspectiva do outro e não somente na sua, resolvendo-o de forma positiva.

No entanto, para que as crianças comecem a pensar em estratégias mais justas e respeitosas para resolverem seus conflitos, a conduta do educador precisa se pautar em relações de diálogo, reciprocidade e empatia. A maneira como o professor lida com tais situações, inclusive abstendo-se qualquer tipo de intervenção, irá interferir diretamente na construção do julgamento moral da criança (VINHA, 2000).

À luz do construtivismo, os conflitos são compreendidos como naturais e necessários ao desenvolvimento do ser humano, principalmente os sóciomorais, sendo vistos como oportunidades favoráveis para a formação de pessoas autônomas. Para DeVries e Zan (1998, p.17) "o ambiente sociomoral é toda rede de relações interpessoais que forma a experiência escolar da criança." Uma atmosfera construtivista na sala de aula é baseada na atitude de respeito do professor pelos interesses, sentimentos, valores e ideias dos alunos e "uma pessoa moral é aquela que decide considerando os outros sempre como iguais" (GILLIGAN, 1982, p.75).

$\mathrm{Na}$ perspectiva da educação tradicional, entretanto, os conflitos são encarados como negativos e prejudiciais. Dessa forma, muitos educadores buscam evitar, tentam conter ou até mesmo resolver as situações de conflitos, impondo regras arbitrárias, sanções expiatórias e utilizando atitudes de coerção, favorecendo assim, a manutenção da heteronomia. Tais ações autoritárias não surtem efeito positivo no comportamento ou desenvolvimento das crianças e os conflitos tendem a aumentar. A concepção de que os conflitos podem colaborar de forma positiva na aprendizagem é negada nesta perspectiva e o foco está apenas nos conteúdos curriculares, excluindo as relações interpessoais desse contexto.

$\mathrm{Na}$ concepção piagetiana o adulto coercitivo orienta a criança para uma moralidade de obediência, enquanto o cooperativo encoraja a autorregularão da mesma por meio de princípios autoconstruídos por ela própria. Portanto, em ambientes onde prevalecem relações de respeito mútuo e reciprocidade, as crianças terão mais chances de construir estratégias mais assertivas, justas e respeitosas a fim de resolverem seus conflitos e alcançarem a autonomia.

Diante da relevância das relações estabelecidas no ambiente escolar, este estudo surgiu da necessidade de refletirmos sobre o desenvolvimento moral da criança, buscando observar as características e o desenvolvimento do ambiente sociomoral de duas escolas particulares, identificando as estratégias utilizadas pelos educadores na mediação dos conflitos interpessoais, bem como propormos possíveis intervenções que visem o desenvolvimento de indivíduos autônomos. 


\section{METODOLOGIA}

A metodologia utilizada neste estudo foi a observação da rotina escolar de crianças e professores do primeiro ano do ensino fundamental I. Para os autores Marconi \& Lakatos, (1996) "A observação na vida real é a observação da realidade, colhendo-se os dados à medida que vai acontecendo o fenômeno, de modo natural".

Vale ressaltar que esta pesquisa foi previamente avaliada e aprovada pelo Comitê de Ética em Pesquisa (CEP), com o protocolo CAAE de no: 69610017.5.0000.5406.

\section{ESCOLAS E PARTICIPANTES}

Participaram desta pesquisa duas escolas da rede particular de ensino de São José do Rio Preto. Ambas as escolas oferecem as três etapas da educação básica. O Ensino fundamental I refere-se ao 1 으 a 50 ano, respectivamente os alunos iniciam o ciclo com seis anos e terminam com dez anos de idade. As instituições têm turmas no período matutino e vespertino, porém a coleta dos dados aconteceu apenas no período vespertino. Para analisarmos como os conflitos são mediados, selecionamos apenas os anos iniciais do ensino fundamental para realizarmos as observações, ou seja, em salas de primeiro ano. Nestas escolas o número de estudantes de cada série varia entre 16 a 19 alunos por sala. O presente estudo aconteceu com aproximadamente 120 crianças e dez professores, sendo sete titulares e três especialistas. Na escola A há quatro salas e na escola B três salas de primeiro ano.

\section{PROCEDIMENTOS}

O procedimento foi a observação das relações de convívio existentes na rotina escolar das crianças, seja na hora da entrada, dentro da sala de aula, nas relações entre os pares, nas condutas dentro da classe e áreas externas, a convivência sem a presença de uma autoridade, como na hora do lanche, por exemplo, após o lanche e na hora da saída. As observações foram registradas em protocolos contendo os seguintes dados: local, sujeitos, idade, descrição do conflito, estratégias de resolução e resultado, e depois foram analisadas e selecionadas as situações mais relevantes. Em cada escola foi realizado um tempo de observação de 30 horas. "Observar é aplicar atentamente os sentidos físicos a um amplo objeto, para dele adquirir um conhecimento claro e preciso", segundo Cervo e Bervian (2002, p.27).

\section{RESULTADOS}

Observa-se na escola A o seu ambiente físico. Na sala de aula encontra-se rádio, armário, cartazes espalhados pela sala nos quais auxiliam os alunos em sua rotina (tais como: calendário, listas de nomes e aniversariantes do mês, e placa para sinalizar se alguém está no banheiro ou não), estante de livros e relógios na parede. As carteiras são organizadas de diferentes maneiras diariamente e a cada atividade o educador tem a oportunidade de usar vários lugares na sala de aula, como exemplo, a roda no chão ou grupos, trios, duplas ou círculos com as carteiras. As crianças não têm lugares fixos, muitas vezes são as professoras que escolhem estes lugares, porém a cada dia a criança senta em lugar diferente.

Antes de iniciar a aula, os alunos do infantil ao primeiro ano, são separados dos demais. Neste espaço reservado, uma vez na semana, as crianças têm a oportunidade de levar brinquedos de casa para a escola. No pátio há cinco adultos, sendo quatro estagiárias e uma inspetora. Os alunos brincam com os objetos trazidos de casa ou ficam esperando a professora chegar. Nas paredes há placas sinalizando o nome de cada série, e é próximo a estas que cada criança fica em sua fila aguardando o momento de entrar para sala.

É notório o tratamento dos adultos com as crianças, os mesmos abaixam para conversar ou mesmo escutar o que as crianças têm a dizer. Não há sinal sonoro para que as crianças se prepararem para entrar, os professores chegam, se posicionam em seus devidos lugares e as 
crianças já entendem que é hora de ir para sala. As filas não são separadas, meninas de um lado e meninos de outros, eles apenas caminham uns próximos aos outros.

Já dentro da sala de aula, é observado que os professores não alteram o tom de voz, os alunos chegam agitados, porém com a noção de sua rotina: colocar a agenda em cima da mesa da professora, comer sua fruta, fazer uma oração e depois iniciar as atividades.

Logo de início são observados os primeiros conflitos:

Enquanto a professora explicava a atividade, $\mathrm{R}$ olha para $\mathrm{V}$ que respondeu errado a questão e diz: "Perdeu Playboy". O amigo ao lado, sentindo-se incomodado responde: "Para R." $\mathrm{R}$ percebe o incomodo e logo para de zombar seu colega.

Esse tipo de conflito aparece várias vezes, ou seja, quando o colega tem a intenção de provocar o outro. Porém, este tipo de situação é logo resolvida, pois os incomodados se defendem dizendo que não estão gostando da atitude do outro, os alunos são ensinados a expressar seus sentimentos. Várias vezes, nota-se que a professora, sempre que solicitada para resolver algum desentendimento, realiza a mediação pedindo para os alunos expressarem o que estão sentindo. Em outras situações em que os alunos não conseguem controlar o próprio corpo, e não param quietos na carteira ou mesmo perturbando sem parar o colega, a professora para o que está fazendo e convida o estudante a conversar do lado de fora da sala de aula. Observa-se que essa é uma forma frequente do educador resolver o conflito.

Durante as atividades, a educadora faz com que a participação dos alunos seja primordial. À vista disso, eles demonstram satisfação e participam, muitas vezes discordam dos colegas, outros concordam.

Conflitos do tipo provocação e exclusão são comuns. Silva (2010/2015) ao estudar os motivos dos conflitos, isto é, os comportamentos que geram os desequilíbrios interpessoais, elaborou a categorização dos conflitos, onde cada um foi analisado buscando conhecer as suas causas, ou seja, quais as ações e motivos que levaram à desavença.

Em outras disciplinas nas quais os professores são especialistas, o comportamento das crianças é o mesmo, não mudando apenas por não estar com o professor responsável pela sala. No lanche, os alunos primeiro sentam para comer, depois limpam o seu lugar, e depois correm, brincam com jogos, bonecas, entre outros, um pouco antes do horário de voltar para a sala, a inspetora já chama pelas crianças e faz brincadeiras com elas à espera da professora. Como são quatro salas de primeiro ano, o horário é dividido. Lancham duas turmas de cada vez.

$\mathrm{Na}$ escola B, antes de bater o sinal para início da aula, os alunos do primeiro ao quinto ano ficam no pátio brincando, correndo e conversando, após o sinal, aguardam a chegada dos professores em fila. Cada série tem seu lugar de espera, onde meninas ficam de um lado e meninos de outro. É observado cinco monitoras para amparar as crianças no que precisar, é notório o carinho dos adultos com as crianças e vice-versa.

Assim que as professoras chegam, cada turma sobe para sua classe. Dentro da sala é observado as carteiras em fileiras diariamente e cada aluno tem seu lugar fixo. Nas paredes há vários cartazes, de alfabeto, de sílabas, de números, atividades já realizadas e alguns do programa que a escola adota, chamado "O líder em mim". No primeiro dia da semana, com auxílio da professora há uma organização na sala em relação a liderança, há o líder da fila, líder da água, da organização, comunicação, do silêncio, da cooperação e da limpeza. Esses líderes têm por objetivo auxiliar a professora a manter um ambiente organizado. As crianças querem e gostam de serem julgadas como líderes. As professoras têm um tom de voz mais alto que o das crianças e chamam a atenção sempre que aparece qualquer desequilíbrio, ou seja, quando há conversa. É notório que as mesmas gostam de um ambiente silencioso, não dando a oportunidade da criança realmente expor o que pensa e o que acha. Uma situação de professor e aluno é descrita abaixo:

Enquanto a professora fala com a sala, o aluno questiona com a professora. A professora retruca dizendo que agora é hora dela falar e o aluno deve esperar. 
Um dos poucos conflitos observados foi da denúncia à professora de que $T$ não estava fazendo a tarefa, e que $\mathrm{G}$ estava conversando. A professora então, resolve o conflito dizendo que falará a diretora o que está acontecendo e pergunta quem gostaria de dar uma voltinha na sala da direção.

Percebe-se que os conflitos são evitados e que os alunos não são ensinados a expressarem seus sentimentos e acabam entendendo que é o adulto que tem a decisão ou mesmo a palavra final.

Durante o intervalo e em outras disciplinas, acontece a mesma coisa. O carinho existe na relação entre professor e aluno, porém o adulto é visto como ser sagrado, sendo assim é sempre este que decide o que fazer e como fazer.

\section{DISCUSSÃO}

No período observado nas escolas $A$ e $B$, os pesquisadores questionaram esporadicamente às crianças sobre as consequências de seus atos. Na escola $A$ foi notório que as crianças entendem que ao receber qualquer tipo de sanção ou mesmo punição, é devido ao motivo da falta de respeito ou mesmo de não saber controlar o próprio corpo, muitas vezes perturbando, agredindo ou mesmo excluindo as pessoas que estão ao seu redor.

Quanto a relação professor e aluno, os estudantes demonstram afeto e respeito para com seu educador, isso mostra a importância da interação tanto no aspecto da aprendizagem quanto na afetividade. Segundo Leão (1999) "o que sempre deve ser enfatizado é que o construtivismo não é, em sentido amplo, uma teoria da educação e não é, em sentido estrito, uma metodologia de ensino. É uma concepção teórica acerca de como o homem chega ao conhecimento, podendo alcançar vários campos da realidade contemporânea".

$\mathrm{Na}$ escola $\mathrm{B}$, quando a criança é questionada sobre o porquê ou para que existem as opções de liderança, o que é ser um líder, o estudante muitas vezes responde que não sabe o motivo pelo qual isso ocorre e entende-se que se faz o que se pede pois quem manda é o adulto, o qual é colocado como ser sagrado.

Já a relação professor e aluno, mostra que o afeto existe, porém, o medo da punição também. Segundo ARAÚJO, (1993) "O valor moral de uma ação não está na mera obediência às regras determinadas socialmente, mas no porquê elas são obedecidas: no princípio inerente a cada ação" e para VINHA (2000) "Através do desequilíbrio a criança é motivada a refletir sobre maneiras distintas de restabelecer a reciprocidade".

\section{CONCLUSÃO}

A presente pesquisa teve por objetivo observar e identificar o ambiente sóciomoral de escolas particulares da cidade do interior paulista. Verificamos que as atitudes dos educadores mediante as relações interpessoais e os conflitos estabelecidos no ambiente escolar, de modo geral, influenciam de forma significativa na formação de um ambiente mais cooperativo ou coercitivo. Se o educador se utiliza de relações de medo e coação com seus alunos, contribuirá para a formação de um ambiente opressivo e indivíduos passivos e conformistas. Porém, em um ambiente onde o autoritarismo do adulto tende a ser minimizado, e as relações são pautadas na cooperação e respeito mútuo, as crianças passarão a levar em consideração os sentimentos e pontos de vista do outro, tornando-se indivíduos mais justos e respeitosos, capazes de regular seu comportamento.

Dessa forma, a escola precisa estar atenta à qualidade das relações que promove, incentivando a educação sociomoral como processo educacional, desprendendo-se de ideais apenas conteudistas e passando a encarar os conflitos como oportunidade para se trabalhar valores. Os pequenos conflitos e desavenças são capazes de permitir meios de resolução que podem levar a um convívio mais saudável, favorecendo a construção de relações sociais. 
Sendo assim, diante desse estudo constatamos a falta de preocupação das instituições em relação a intervenção do desenvolvimento da autonomia da criança, a partir de um ambiente sociomoral, pois o foco principal muitas vezes, é fazer com que o aprendiz tenha "bons comportamentos". Torna-se, portanto, a necessidade da criação de ambientes cooperativos e reflexivos, oportunizando o diálogo e a exposição de sentimentos a partir das situações de conflitos interpessoais.

\section{REFERÊNCIAS}

ARAÚJO, U. F. Um estudo da relação entre o ambiente cooperativo e o julgamento moral na criança. Dissertação de Mestrado, Faculdade de Educação, Unicamp, Campinas, SP. 1993.

CERVO, A. L. BERVIAN, P. A. Metodologia científica. 5.ed. São Paulo: Prentice Hall, 2002.

DEVRIES, R.; ZAN, B. A ética na educação infantil: o ambiente sociomoral na escola. Tradução de Deyse Batista. Porto Alegre: Artmed, 1998.

GILLIGAN, C. Uma voz diferente. Rio de Janeiro: Rosa dos Ventos, 1982.

LEAO, Denise Maria Maciel. Paradigmas Contemporâneos de Educação: Escola Tradicional e Escola Construtivista. Caderno de pesquisa., São Paulo, 1999.

LICCIARDI, L. M. S. Investigando os conflitos entre as crianças na escola. 2010. Dissertação (Mestrado em Educação). Faculdade de Educação, Universidade Estadual de Campinas, Campinas, 2010.

MARCONI, M. A; LAKATOS, E. V. Metodologia científica. São Paulo: Editora Atlas, 2004.

SILVA, L. M. F. da. Conflitos entre alunos de 8 e 9 anos: causas, estratégias e finalizações. 2014. 233 p. Tese (doutorado) - Universidade Estadual de Campinas, Faculdade de Educação, Campinas, SP.

VINHA, T. P. O educador e a moralidade infantil uma visão construtivista. 3. ed. Campinas: Mercado de Letras, 2000. 